\title{
OS MICRO MACHISMOS NO CURSO DE ADMINISTRAÇÃO DA UFPEL
}

\section{MICRO MACHIMOS EN EL CURSO DE ADMINISTRACIÓN DE LA UFPEL}

\author{
MICRO MACHISMS IN THE UFPEL MANAGEMENT GRADUATION
}

\author{
Ana Paula Timm Krolow ${ }^{1}$ \\ ORCID: https://orcid.org/0000-0002-8083-865X \\ Marcio Silva Rodrigues ${ }^{2}$ \\ ORCID: https://orcid.org/0000-0002-8810-7077
}

Submissão: 15/01/2021 / Aceito: 07/06/2021 / Publicado: 30/09/2021.

\begin{abstract}
Resumo
O termo micro machismo combina dois elementos: machismo como atitude de quem crê que o homem é socialmente superior à mulher; e a perspectiva foucaultiana de "micro" poder, referente às práticas discursivas capilares. Assim, entende-se micro machismos como práticas e discursos naturalizados, baseados nos valores históricos de uma sociedade patriarcal, e reproduzidas socialmente, que contribuem para a perpetuação da dominação masculina. Este estudo verificou a ocorrência destas práticas e analisou-as dentro do curso de Administração da Universidade Federal de Pelotas (UFPel), buscando promover o debate sobre gênero no curso, e contribuir para os estudos críticos de gênero na área. Apesar de interseccionadas, para fins de análise, as práticas foram agrupadas em quatro categorias: a idealização, a objetificação, a masculinização e a deslegitimação da mulher. A coleta de informações se deu através de questionários, aplicados em 206 dos 490 alunos, verificando a percepção destes sobre a ocorrência das práticas, e, posteriormente, a escuta de quatro relatos voluntários. Através da análise, foi possível constatar a ocorrência das quatro formas de micro machismos investigadas. A mais recorrente é a idealização da mulher, pois $67 \%$ dos alunos afirmaram ter ouvido comentários envolvendo o estereótipo da mulher ideal, delimitando áreas de atuação. Por meio das respostas objetivas, a noção de objetificação da mulher e de seu corpo (62\%), a ideia de que a figura caracterizadamente masculinizada representa responsabilidade, tanto na universidade quanto no mercado de trabalho, e o questionamento da credibilidade das mulheres (38\%) também estão nas falas e ações do ambiente do curso
\end{abstract}

Palavras-chave: Estudos de Gênero. Micro Machismo. Curso de Administração. Universidade Federal de Pelotas.

\begin{abstract}
The term micro machisms combines two elements: machism attitude as of those who believe that men are socially superior to women; and the Foucaultian perspective of "micro" power, referring to capillary discursive practices. Thus, micro machism is understood as naturalized practices and discourses, based on the historical values of a patriarchal society, and reproduced socially, which contribute to the perpetuation of male domination. This study verified the occurrence of these practices and analyzed them within the managemente course of the Universidade Federal de Pelotas (UFPel), seeking to promote the debate on gender in
\end{abstract}

\footnotetext{
${ }^{1}$ Mestre em Sociologia. Universidade Federal de Pelotas (UFPel). E-mail: anapaulatkrolow@gmail.com.

${ }^{2}$ Doutor em Administração. Universidade Federal de Pelotas (UFPel). E-mail: marciosilvarodrigues@gmail.com.
} 
the course, and to contribute to the mandatory gender studies in the area. Despite being intersected, for the purposes of analysis, the practices were grouped into four categories: idealization, objectification, masculinization and delegitimization of women. The collection of information took place through questionnaires, given in 206 of the 490 students, verifying the perception about the occurrence of the practices, and, later, listening to four voluntary reports. Through the analysis, it was possible to verify the occurrence of the four forms of micro machismo investigated. The most recurrent is the idealization of women, as $67 \%$ of students claim to have heard comments involving the stereotype of the ideal woman, delimiting areas of activity. Through objective responses, the notion of objectification of women and their bodies (62\%), the idea that a characterized male figure represents responsibility, both in the university and in the job market, and the questioning of women's credibility (38\%)) are also in the speeches and actions of the course environment.

Keywords: Gender Studies. Micro Machisms. Management Graduation. Universidade Federal de Pelotas.

\section{Resumen}

El término micro machismo combina dos elementos: el machismo como actitud de quienes creen que los hombres son socialmente superiores a las mujeres; y la perspectiva foucaultiana del "micro" poder, refiriéndose a las prácticas discursivas capilares. Así, el micro machismo se entiende como prácticas y discursos naturalizados, basados en los valores históricos de una sociedad patriarcal, y reproducidos socialmente, que contribuyen a la perpetuación de la dominación masculina. Este estudio verificó la ocurrencia de estas prácticas y las analizó dentro del curso de Administración de la Universidad Federal de Pelotas (UFPel), buscando promover el debate sobre género en el curso y contribuir a los estudios críticos de género en el área. A pesar de estar cruzadas, a los efectos del análisis, las prácticas se agruparon en cuatro categorías: idealización, objetivación, masculinización y deslegitimación de la mujer. La información fue recolectada a través de cuestionarios, aplicados a 206 de los 490 estudiantes, verificando su percepción de la ocurrencia de prácticas $\mathrm{y}$, posteriormente, escuchando cuatro informes voluntarios. A través del análisis, fue posible verificar la ocurrencia de las cuatro formas de micro machismo investigadas. La más recurrente es la idealización de la mujer, ya que el $67 \%$ de los estudiantes dijo haber escuchado comentarios sobre el estereotipo de la mujer ideal, delimitando áreas de actividad. A través de respuestas objetivas, la noción de cosificación de la mujer y su cuerpo (62\%), la idea de que la figura masculina caracterizada representa responsabilidad, tanto en la universidad como en el mercado laboral, y el cuestionamiento de la credibilidad de la mujer (38\%) también están en los discursos y acciones del entorno del curso.

Palabras chave: Estudios de género. Micro Machismo. Curso de administración. Universidad Federal de Pelotas.

\section{INTRODUÇÃO}

O presente estudo tem como objetivo geral analisar a presença de práticas de micro machismos dentro do curso de Administração da UFPEL. Unindo a descrição adotada ao longo do trabalho de machismo - "atitude ou comportamento de quem não admite a igualdade de direitos para o homem e a mulher" - e a noção de "micro" estabelecida por Foucault (1979), que remete às práticas discursivas capilares, quase "invisíveis", formou-se 
o título do trabalho com a expressão "Micro Machismos". Esta expressão reflete com precisão as práticas investigadas ao decorrer da pesquisa dentro do objeto de estudo selecionado, práticas e discursos naturalizados reproduzidos em um determinado ambiente e que contribuem para a perpetuação da desvalorização da mulher. (LOURO, 1995; SCOTT 1989)

O interesse pela universidade tem dois motivos principais: a premissa de que a universidade deve ser um ambiente democrático, plural e acolhedor, e que promove o desenvolvimento de conhecimento a todos de forma igual, porém este ambiente não existe enquanto houver segregação e preconceito de qualquer forma; e também, mais precisamente o curso de Administração, por estar diretamente relacionado com a formação de pessoas atuantes no mercado de trabalho e nas empresas, instituição que também tem grande influência no modo de organização da sociedade como um todo.

Posto isso, a estrutura do trabalho consiste nessa primeira de introdução sobre o tema abordado e justificativas pertinentes, em seguida um apanhado teórico sobre os temas abordados, uma breve descrição da metodologia utilizada no decorrer da pesquisa, seguido da análise dos dados coletados juntamente aos alunos do curso, e por fim, uma sessão dedicada às considerações finais do estudo realizado.

\section{ALGUNS APONTAMENTOS TEÓRICOS}

\section{Gênero e Feminismo}

As desigualdades de gênero que persistem em existir na sociedade são fruto de um processo histórico de práticas assimétricas de poder. A cultura masculinizada, visivelmente transposta a diversas esferas sociais, tem sua origem e perpetua-se através de uma sociedade patriarcal e de um discurso machista. O patriarcado é considerado um dos mais antigos sistemas de opressão (SCOTT, 1989) e, em suma, pode ser definido como o modo de organização social onde há a preponderância masculina, quando a autoridade é exercida pelos homens, remetendo à figura do patriarca, cuja função era a de ser o chefe de família.

Para compreender esta separação entre feminino e masculino, é necessário entender, também, o conceito de gênero. Sob a ótica dos estudos feministas, gênero não é apenas uma diferenciação gramatical, representada pelo feminino, masculino e neutro, e sim uma maneira de "referir-se à organização social da relação entre os sexos" (SCOTT, 1989) e, além disso, 
resultado da construção social das características atribuídas a cada um, e da dicotomia inserida na relação entre eles.

A luta pela igualdade de gênero, através do movimento feminista, ocorre da união de prática e teoria, da realidade dos movimentos sociais ao dialogar com o feminismo acadêmico e as correntes teóricas. Em um texto que sistematiza os estudos de gênero, Joan Scott (1989) insere-o como categoria de análise histórica, e consequentemente explana e critica os diversos estudos que buscavam analisar as desigualdades, ao longo das fases do feminismo.

As diferentes ondas do feminismo ocorreram em épocas distintas, com possibilidades e contextos históricos e políticos definidos. A respeito da primeira onda, pode-se dizer que representa o movimento sufragista pela igualdade de direitos civis, educativos e políticos, situado principalmente na Inglaterra, França, Estados Unidos e Espanha, tendo como uma das principais bandeiras o direito ao voto. Esta primeira fase é responsável pela denúncia das imposições por parte do patriarcado (SCOTT, 1989; NARVAZ, KOLLER, 2006). A segunda onda surge nas décadas de 1960 e 1970 é marcada pela busca pela igualdade e pelas problematizações envolvendo o "ser mulher", apresentando a quebra entre sexo biológico e gênero, representada pela frase emblemática: "Ninguém nasce mulher, torna-se" (BEAUVOIR, 1980, p.9). Esta fase é conhecida como "feminismo da igualdade", e a divisão entre sexo e gênero funda a base teórica feminista da época. Já a terceira onda feminista, pós a década de 1980, recebe influência da crítica pós-modernista, e abre o debate ao que se denomina "feminismo da diferença”" (BUTLER, 2003; NARVAZ, KOLLER, 2006; LOURO, 1995). É evidenciado nessa fase o quanto o discurso generalista é, na verdade, excludente, ignorando os recortes de classe, raça, e outras especificidades do feminino. Butler (2009) é referência teórica da terceira onda, ao desconstruir o conceito binário de gênero, e questionando o papel da mulher como sujeito único do feminismo (BUTLER, 2009; LOURO, 1995).

\section{Estudos de Gênero e a Administração}

Conectando os estudos feministas de gênero com a área de administração, é possível citar Simone de Beauvoir quando diz que

Economicamente, homens e mulheres constituem como que duas castas; em igualdade de condições, os primeiros têm situações mais vantajosas, salários mais altos, maiores possibilidades de êxito que suas concorrentes recém-chegadas. 
Ocupam na indústria, na política etc., maior número de lugares e os postos mais importantes (BEAUVOIR, 1980, p.14-15).

Desde a publicação da obra passaram-se 67 anos e, apesar de várias conquistas femininas, desde as mais básicas, como o direito a voto e leis de proteção a mulher, até melhores condições também no ambiente de trabalho, como a licença maternidade e maior presença das mulheres nas empresas e instituições, a afirmação de Beauvoir ainda é verdadeira. Em um relatório chamado Women in business and management: gaining momentum, publicado em 2015 pela Organização Internacional do Trabalho, muitas das disparidades entre homens e mulheres são expostas. Esse estudo, analisou empresas de 80 países, revela que apesar de um aumento no número de mulheres em posição de gerência em empresas em relação ao último estudo, que hoje é de cerca de 30\% (em sua maioria em empresas de pequeno e médio porte), elas representam apenas $5 \%$ dos cargos de alta gerência em grandes empresas. Esse mesmo relatório aponta que a respeito dos conselhos e juntas diretivas, $30 \%$ das empresas não tem mulheres na sua formação, e cerca de $65 \%$ tem menos de $30 \%$ de participação feminina nos grupos decisórios, demonstrando a falta de confiabilidade na capacidade das mulheres.

Sobre a inserção no mercado de trabalho, um outro relatório da OIT de um estudo realizado com empresas do Brasil, Argentina, Chile e México desqualifica o argumento que “justifica” o menor número de mulheres (ABRAMO, 2016), de que a mulher representa um gasto maior para o empregador, geralmente atrelando as despesas aos gastos com a maternidade. Segundo essa pesquisa, os custos monetários para o empregador relacionado a contratação das mulheres são muito reduzidos, representam menos de $2 \%$ da remuneração mensal bruta.

Há também uma grande diferença salarial entre homens e mulheres, mesmo quando apresentam a mesma carga horária de trabalho. De acordo com dados do mesmo relatório citado anteriormente, no Brasil essa disparidade para quem trabalha 40 horas semanais é de $20,32 \%$, ou seja, caso homens e mulheres trabalhem iguais 365 dias por ano, as últimas recebem por apenas 291 deles.

Inicialmente, estes números são justificados por alguns pressupostos. Primeiramente é argumentado que as mulheres recebem menos por exercerem atividades com menor retorno financeiro, em comparação às atividades exercidas pelos homens, entretanto elas são condicionadas à estas atividades, citadas por Fonseca como predominantemente assistenciais, por estímulos feitos desde a infância (FONSECA, 2000). O relatório da OIT de 
2015, anteriormente citado, apresenta a consequência da segregação de gênero dentro das empresas, ou seja, a atribuição de determinados cargos como femininos ou masculinos, como um dos principais motivos pelo baixo número de presença feminina nos cargos de alta gerência, pois assim, as mulheres não conseguem obter experiência suficiente dentro da própria companhia para estarem aptas às posições hierarquicamente superiores. Este mesmo relatório traz os termos "paredes de vidro" e "teto de vidro" como modo de reprodução do machismo dentro das organizações, termos estes que Steil trabalha em seu artigo, referindose, respectivamente, às barreiras culturais que impedem as mulheres de trabalharem em determinadas áreas da empresa, como vendas e finanças, e, consequentemente, de coordenála (STEIL, 1997).

Compreende-se então que a diferenciação no âmbito social ocorre ao atribuir certas características, comportamentos ou funções a condições biológicas de cada sexo, como por exemplo, ao delegar à mulher as responsabilidades do lar, ao se avaliar a feminilidade através de um conjunto de características da personalidade da "verdadeira mulher" (termo usado por Beauvoir) como a fragilidade e delicadeza, e em contrapartida a masculinidade também, com a repressão de todos os aspectos femininos e valorização da virilidade, e, assim, determinar o papel que cada um desempenha. É fácil visualizar essa organização na sociedade, porém não é tão fácil compreender como ela se constitui, quais mecanismos tornam essas atribuições "naturais".

Visando facilitar esta compreensão, Scott (1989) enumera algumas maneiras desta legitimação acontecer, sendo as mais relevantes para este trabalho: os símbolos culturalmente disponíveis que expõe representações múltiplas, e muitas vezes antagônicas, como as figuras de Eva e Maria, exemplificando de um lado a pecadora, e de outro a santa, estigmatizando condutas e comportamentos, já diretamente ligado com um outro ponto da legitimação; os conceitos normativos que colocam em evidência "interpretações dos símbolos que tentam limitar e conter as suas possibilidades metafóricas" (p.21) e; a premissa de que o gênero é construído e disseminado através do patriarcado, porém não exclusivamente por ele, é igualmente representado na economia, na organização política, instituições religiosas e etc. Este mesmo raciocínio pode ser transposto para o ambiente do mercado de trabalho, e acaba resultando nas diferenciações citadas anteriormente.

Tais segregações de gênero, no mercado de trabalho e fora dele, permanecem "naturais" mesmo após décadas de estudos feministas desmistificando as diferenças biológicas e psíquicas e lutas dos movimentos sociais, e a explicação para isto está 
relacionada com a segunda característica que Joan Scott atribui ao conceito de gênero, quando o classifica como uma forma primária de significar relações de poder (SCOTT, 1989).

\title{
Gênero e Poder
}

Scott introduz, no mesmo estudo citado anteriormente, uma visão essencial para entender a dinâmica entre o machismo e as relações de poder, e consequentemente as relações de trabalho, substituindo a noção de poder social como algo centralizado e unificado por “alguma coisa que esteja mais próxima do conceito foucaultiano de poder" (SCOTT, 1989, p. 20), autor amplamente utilizado nos estudos de gênero em geral.

Foucault (1979) com a noção de microfísica do poder, desorganiza as concepções tradicionais, e elimina a ideia de que o poder está em uma estrutura central, que o detém e dissemina em uma única direção, e defende que ele é descentralizado, dissipado em várias direções, e está inserido em todas as relações de forma capilar, agindo como mecanismo de manutenção de uma rede, como um conjunto de práticas sociais e discursos historicamente construídos, que assim, disciplinam os indivíduos e grupos, focando principalmente no modo como ocorre a dominação e a subordinação a este. (LOURO, 1999). É desta forma que esse conceito de poder desqualifica a polarização que coloca em oposição o dominante e o dominado.

Através desta análise, é possível afirmar que o machismo é a prática, o dispositivo discursivo, nos termos foucaultianos, que está incorporado em todas as dinâmicas e relações, que legitima a desvalorização da mulher e torna 'verdade' os valores que constroem, e são construídos pela sociedade patriarcal. Ainda sobre esta construção, Foucault ilustra:

\begin{abstract}
A verdade é deste mundo; ela é produzida nele graças a múltiplas coerções e nele produz efeitos regulamentados de poder. Cada sociedade tem seu regime de verdade, sua "política geral" de verdade: isto é, os tipos de discurso que ela acolhe e faz funcionar como verdadeiros; os mecanismos e as instâncias que permitem distinguir os enunciados verdadeiros dos falsos, a maneira como se sanciona uns e outros; as técnicas e os procedimentos que são valorizados para a obtenção da verdade; o estatuto daqueles que têm o encargo de dizer o que funciona como verdadeiro (FOUCAULT, 1979, p.12).
\end{abstract}

Outra característica abordada por Foucault contrasta com as noções tradicionais de poder, a ideia de que o poder não é apenas negativo e coercitivo, mas também produtivo e positivo (LOURO, 1995). Estas micro práticas, aparentemente banais, não apenas coíbem e 
proíbem, mas também acabam por produzir sujeitos, fabricando corpos dóceis, incitando comportamentos "aceitáveis", e diminuindo a força política dos indivíduos (MACHADO, 1993).

Considera-se, então, o machismo como uma construção discursiva mantida por micro práticas, ou seja, práticas corriqueiras, aparentemente pequenas, quase imperceptíveis que, em conjunto com outras, acabam constituindo uma relação de dominação. Esta dominação implica em ideias, discursos, comportamentos inseridos muito profundamente em toda a sociedade, incluindo também a esfera econômica e das relações de trabalho, ou então as instituições educacionais, que desempenham um papel determinante na manutenção desse discurso, tendo em vista o seu papel de promover o aprendizado e a reflexão nos indivíduos.

\section{METODOLOGIA}

Considerando que este trabalho visa tanto verificar a ocorrência das práticas dos micro machismos quanto, se existentes, descrevê-las, optou-se por realizar o estudo em duas etapas, uma primeira fase predominantemente quantitativa, e posteriormente uma análise qualitativa. Neste estudo, em especial, a abordagem inicialmente quantitativa é necessária, tendo em vista que o tema escolhido, assim como os estudos de gênero em geral, é pouco abordado e compreendido no universo da pesquisa. Portanto optou-se pela análise desta forma para, primeiro, obter um panorama geral da ocorrência dos machismos no curso e da percepção do tema pelos alunos, e também facilitar a abordagem para a segunda etapa do trabalho.

As questões feitas pretendiam exemplificar as práticas micro machistas mais comuns dentro das universidades, e foram elaboradas com base, principalmente, nos conceitos de gênero de Scott (1995), de naturalização de Beauvoir (1980), nas práticas ligadas à educação abordadas por Louro (1999) e nas experiências vividas em sala por uma autora deste artigo. O curso, no período estudado, contava com 490 alunos matriculados, entretanto, devido as ausências em sala de aula, foram respondidos 206 questionários, sendo estes 98 vindos de alunas e 108 de alunos. Após a aplicação pessoal destes questionários, os resultados foram tabulados, e iniciou-se a análise dos mesmos.

Como foi citado anteriormente, é interesse do trabalho dar voz às mulheres, e assim descrever também como ocorrem estas práticas machistas. Sendo assim, foram ouvidas 
quatro alunas mulheres do curso, que prestaram depoimentos voluntários relatando situações vividas ou presenciadas. As entrevistas não continham um roteiro pré-determinado, pois a ideia era realmente levantar manifestações espontâneas, que retratassem os acontecimentos sob o ponto de vista das entrevistadas. Após as entrevistas, os relatos foram transcritos e posteriormente analisados.

Afim de facilitar a análise dos dados coletados, as informações reunidas foram organizadas e agrupadas em quatro categorias de análise construídas para o estudo, sendo elas a idealização, a objetificação, a masculinização e a deslegitimação da mulher. A teorização acerca destas categorias é feita juntamente com a análise e reflexão dos dados obtidos. Em conjunto com as informações verificadas, é importante ressaltar que a primeira autora deste texto é mulher e foi, durante a realização da pesquisa, aluna do curso de administração, ou seja, além de observadora, ela foi também, em alguns casos, testemunha e vítima deste processo e, portanto, o papel de observadora ajuda a enriquecer as informações coletadas.

Por fim, consideramos pertinente mencionar algumas limitações encontradas para a realização da pesquisa. Primeiro, como mencionado anteriormente, não foi possível aplicar os questionários com o número total de estudantes, principalmente pelo grande número de alunos faltantes. Também pode ser observada a resistência de alguns professores quanto a passagem em sala de aula, principalmente ao saber do que se tratava a pesquisa.

\section{ANÁLISE DE DADOS}

O presente estudo trata-se de um trabalho essencialmente empírico, e se propõe a descrever e analisar a ocorrência e as consequências do fenômeno dos micro machismos, e não o fenômeno em si. Assim justifica-se a ausência de um capítulo específico de fundamentação teórica das categorias de análise, pois a mesma se dará ao longo da própria análise, tornando então o trabalho mais fluido e colocando em evidência os dados coletados. Apesar das práticas estarem fortemente interseccionadas, todos os dados, tanto dos questionários quanto dos relatos, foram agrupados em quatro categorias principais de práticas dos micro machismos, a fim de facilitar a teorização e a compreensão, e são elas: a idealização, a objetificação, a masculinização e a deslegitimação. 


\section{Idealização}

A idealização da mulher se dá através das práticas que reproduzem um estereótipo machista construído e perpetuado socialmente, que estabelecem uma forma de ver e representar a mulher. Contribuindo com esta ideia, Chies defende que a "inferioridade feminina é delineada pelos estereótipos remetidos às mulheres", e sendo assim, podem ser considerados instrumentos de preconceito e dominação. (CHIES, 2010 p. 512)

Imputar à feminilidade características como a fragilidade, o cuidado, a pureza, a responsabilidade pelos cuidados do lar por exemplo, é consequência dessa naturalização. Tudo isso está muito ligado idealização também da família, onde a mulher é estigmatizada, e essa concepção costuma ser transposta as empresas e demais organizações (FONSECA, 2000). Sendo assim, os dados da diferença entre homens e mulheres no mercado de trabalho apresentados na introdução do estudo são, em parte, justificados. Ao incorporar a construção dos papéis de gênero, o mercado de trabalho atrela o trabalho feminino esse caráter de 'cuidar de', determinando profissões ou áreas em que este perfil se encaixa ou não, e além disso, desvaloriza essas profissões ou áreas em detrimento das então tidas como masculinas, que são vistas com maior rentabilidade (CHIES, 2010). Uma das questões do questionário pretendia investigar a ocorrência de práticas que estimulam a perpetuação desse estereótipo em sala de aula. Estes foram os dados quantitativos mais expressivos encontrados no trabalho, confirmando a naturalização deste comportamento.

Foi perguntando aos alunos no geral se já haviam presenciado alguma fala que promovesse o estereótipo machista da mulher alguma vez em sala de aula. Os resultados foram similares entre os homens e mulheres, onde $77 \%$ afirmaram que já presenciaram. Foi perguntado também quem havia feito tal comentário, e $81 \%$ dos alunos afirmaram que estes foram feitos por alunos, em seguida de uma porcentagem também alta de falas vinda de professores, $66 \%$.

Há a ocorrência também do machismo reproduzido pelas mulheres, como demonstrado nos altos números de atos praticados por alunas e professoras em todas as questões. Esta circunstância encontra fundamentação na perspectiva de poder de Foucault, anteriormente citada, que utilizada nas relações de gênero, acaba com a polarização entre o masculino e o feminino, exclui a ideia inicial de que um dos sujeitos detém o poder e o outro apenas está submetido a ele. $\mathrm{O}$ autor caracteriza esse fenômeno como um efeito disciplinante 
do poder, que ao induzir comportamentos, reduz também a capacidade de resistência e contestação. (FOUCAULT, 1989)

Alguns exemplos coletados nos relatos voluntários corroboram com os números encontrados. É constante a atribuição de tarefas às mulheres e a exclusão da responsabilidade dos homens nos conteúdos de marketing, por exemplo. A Aluna 3 conta que o professor instrui que as propagandas relativas à produtos de limpeza devem ser direcionada as mulher, e se incomoda com os "vários comentários em sala de aula de produtos de limpeza, dizendo que quem entende são as mulheres né, homens não chegam nem perto disso então não entendem".

A Aluna 2 expõe, também, um exemplo de comentário desvinculado do conteúdo das aulas, realizado por um outro professor. Ela relata quem em uma aula, a turma no geral conversava bastante, atrapalhando o andamento da aula, e depois de um certo tempo o professor se incomodou com este fato, e resolveu pedir para duas alunas se retirarem do ambiente, completando o pedido com a frase "vão para casa ver novela". O professor, ao fazer este comentário desnecessário, imprime a ideia de que o lugar das alunas não é na sala de aula, e a aluna complementa "ele não diria isso se fossem meninos".

Através dos relatos pode-se constatar, inclusive, que os comentários não se detêm apenas na sala de aula, mas que ocorrem também nos corredores da faculdade. A Aluna 1 presenciou uma destas ocorrências, quando um professor, ao encontrar duas mulheres que ela acredita serem professoras do curso também, falou que "duas mulheres juntas conversando só poderiam estar falando de homem né, no caso o marido, ou então de celulite".

Analisando os dados quantitativos, e os exemplos citados pelas alunas, pode-se perceber que os comentários machistas são comuns no ambiente do curso, e que este comportamento é visto como natural pela maioria dos alunos.

\section{Objetificação}

A objetificação da mulher, ou seja, o ato sexista de tratar a mulher como um objeto, podendo assim observá-la e julgá-la como bem entender, foi abordada na primeira pergunta do questionário aplicado às mulheres. Este item também está diretamente ligado ao estereótipo da "mulher ideal" (abordado no item 4.1) e à masculinização imposta (item 4.3), porém por ora a análise se deterá na primeira prática citada. 
A categoria busca explicitar a ocorrência de práticas que repreendem as alunas na sala de aula e no ambiente do curso quanto ao seu jeito de vestir e de agir, remetendo assim à ideia de que existe uma forma "correta" de se portar e se apresentar nesse ambiente. Feita a pergunta, aproximadamente $62 \%$ das alunas respondentes afirmaram terem sofrido olhares ou comentários constrangedores. Logo em seguida foi indagado quem realizou tal ação ou comentário (nestas questões é possível marcar mais de uma opção). É possível concluir pelas respostas que a prática é rotineira entre os alunos do curso, pois $75 \%$ das alunas afirmaram que já sofreram algum tipo de repressão deste tipo por alunos, e $45 \%$ por alunas. O relato da Aluna 4 dá o exemplo de uma ocorrência em sala de aula por parte de colegas: “[...] lembro de uma vez que um colega meu falou que o meu short tava muito curto e eu não sei o que passou na cabeça dele pra achar que ele podia fazer um comentário desses”.

Também é elevado o número de alunas constrangidas por professores, cerca de $28 \%$ e os exemplos trazidos pelas alunas ouvidas explicitam situações que ocorrem inclusive dentro de sala de aula. Em seu depoimento, a Aluna 3 fala de uma experiência direcionada diretamente a ela, quando incomodou-se com os olhares de um professor durante uma aula. A aluna vestia o uniforme de trabalho, e o professor a olhava insistentemente. A aluna ainda comenta que tentou amenizar a situação “[...] eu fechei (a camisa), puxei os cabelos pra frente assim, pra dar uma disfarçada, e ele seguiu, continuou olhando e olhando". A Aluna 2, que presenciou este mesmo ato, comenta que esta situação é recorrente com este mesmo professor, e ainda complementa dizendo que se sente "[...] abusada praticamente pela maneira como ele nos olha, como se a gente pudesse ser um objeto, sabe? É horrível!". Entretanto, justamente pelas suas sucessivas repetições, estes atos acabam se naturalizando e passam a ser práticas comuns, e isto justifica a ausência destes nos exemplos e a predominância dos casos envolvendo professores, como pode ser ilustrado na fala da Aluna 2: “[...] e não é porque a gente não percebeu, é porque a gente aceita né, aquilo é natural pra gente já, então a gente aceita e lembra só dos casos mais gritantes”.

\section{Masculinização}

É perceptível na sociedade que as profissões mais tradicionais, as que possuem um maior prestígio, são profissões que tem origem masculina, e que até hoje são ocupadas predominantemente por homens. (BEAUVOIR, 1980; CHIES, 2010). Considerando que, como mencionado anteriormente, os papeis de gênero são construídos socialmente, há, 
também, um conjunto de características e comportamentos que formam o padrão masculino aceito para ocupar estas profissões ou áreas.

Nas declarações das alunas voluntárias é possível identificar comentários que reproduzem estas condições. É consenso entre as aulas que a figura do administrador "ideal" é exposta claramente no curso, como exemplifica a Aluna 3: "o perfil do administrador é óbvio, é um homem de terno, gravata e uma pastinha, esse é o cara que tem sucesso, o restante dos alunos vão ser assistentes administrativos, auxiliares, e que se conformem com isso". A mudança imposta no comportamento da mulher começa dentro da universidade, e nas palavras da Aluna 2, as mulheres são "pressionadas a agir de forma masculinizadas, não são nem encaminhadas, mas sim encurraladas”. Esta pressão começa nas pequenas coisas, como, por exemplo, a forma de apresentação dos trabalhos, as alunas não podem vestir qualquer roupa que desejarem, independentemente da temperatura que esteja no dia, ou então "dar ataque de mulherzinha", como define a Aluna 2, para que seja minimamente respeitada.

Durante as aulas são expostas também as práticas machistas naturalizadas no mercado de trabalho, reforçadas pelas opiniões pessoais dos professores. Dentre os exemplos identificados nos relatos, pode-se citar a situação da Aluna 1, que presenciou um professor afirmar em sala de aula que a licença maternidade era um absurdo e, ao tentar argumentar a favor, foi silenciada pelo professor juntamente com outros colegas. Outra ocorrência foi exposta pela Aluna 2, que concorda que o mercado e a sociedade por si só já impõe essa masculinidade às mulheres, mas que a universidade colabora fortemente, como quando um professor falou "que se tu tem filhos o problema é teu, sabe? Tu que dê um jeito!".

\section{Deslegitimação}

Outro modo de desvalorizar a mulher é diminuir a sua importância, seja desconsiderando suas opiniões, desmerecendo sua capacidade, ou até mesmo privando-a do seu espaço de fala. Esta tende a ser a mais "sutil" das práticas abordadas no trabalho, devido ao seu grau de naturalização. Homens e mulheres são acostumados com essa ideia desde cedo, pois ela é replicada no ambiente familiar, no ensino básico, nas universidades, no trabalho, por exemplo. Ela personifica-se na figura do pai, do colega, do professor, do namorado, do chefe, exemplos que costumam ter a voz mais forte, a palavra final, o argumento mais válido, maior credibilidade ou a autoridade mais crível. Cerca de $31 \%$ das alunas afirmam já terem passado por algum constrangimento semelhante na sala de aula e, 
assim como em todas as outras questões feitas, na maior parte praticado por alunos (63\%) e professores $(53 \%)$, porém com significativo aumento se comparado com as outras questões de atos feitos por outras alunas, perto de $37 \%$.

As alunas que deram seu depoimento trouxeram múltiplos exemplos destas práticas, evidenciando as várias formas de ocorrência. A primeira aluna entrevistada conta que é vítima frequente de ações deste tipo. Em um primeiro momento, relata que os próprios colegas, tanto homens quanto algumas mulheres, já desconsideram suas opiniões quando tenta argumentar com os professores. Citou, por exemplo, o caso analisado anteriormente, quando um professor se posicionou contra a licença maternidade. Nesta ocasião, ela e mais uma colega apresentaram argumentos favoráveis, porém foram silenciadas por argumentos fora de contexto pelo professor, que ainda contou com o apoio dos colegas presentes em sala de aula.

Ela ainda expõe outro comportamento comum dos colegas de turma, a tendência de determinar os conteúdos que se deve ouvir a opinião das mulheres e os assuntos que não as competem. A aluna conta que "em algo específico de alguma matéria, como marketing ou finanças, eles nos contestam porque eles acham que o que uma mulher ta falando não tem credibilidade sabe? Então nem se prestam a pesquisar, mas eles já vão lá e cortam o que tu ta falando". Beauvoir (1980) afirma que a sociedade pode iludir-se que não existe mais hierarquia social entre os sexos, porém, a certas inferioridades, principalmente a incapacidade profissional, atribui à natureza, as causas biológicas. Atitudes como esta citada pela aluna acabam delimitando o papel das mulheres tanto na sala de aula e na administração, como na sociedade em geral com base em crenças infundadas. Como consta no depoimento da Aluna 4, que ouviu um professor comentar que a "faculdade está mal administrada porque tem mulheres desempenhando essa atividade".

Uma outra forma, ainda mais constrangedora, de expor esta suposta incapacidade feminina é, justamente, explicita-la ao mesmo tempo que incentiva o oposto, que enaltece a superioridade masculina. A Aluna 2 menciona uma prática recorrente de um professor, que, segundo ela, claramente faz perguntas mais difíceis direcionadas as mulheres, e rapidamente, sem dar o tempo necessário de resposta, fala "ah, se tu não sabe responder vou perguntar para o fulano", dando a chance dos alunos então responderem a pergunta.

Por último, é relatado um caso ainda mais grave, quando um conjunto de práticas relacionadas ao machismo e outras formas de intolerância tem consequências maiores, afetando diretamente a aluna de uma forma pessoal. A Aluna 1 conta que esta foi a vez que 
se sentiu mais humilhada e desamparada, e após o ocorrido pensou até mesmo em desistir do curso. O caso ocorreu quando a aluna se candidatou a uma vaga de representante discente, e em uma reunião com a presença dos outros candidatos, de um professor, e uma professora, deveria expor suas motivações e porque estava se candidatando. Ela menciona que ao chegar a sua vez de falar, um aluno interrompeu e disse que "descobriu na 'rádio corredor' que eu era envolvida com partidos políticos, que eu tinha posições radicais e que eu não teria caráter ou ética para assumir este cargo". Agravando ainda mais a situação, os professores presentes no momento, em vez de repreender a atitude do rapaz, instigaram ainda mais o debate, e pressionaram a aluna a responder sobre suas preferências políticas, e logo em seguida ser retalhada por isso, tanto pelos professores quanto pelos alunos.

\section{CONSIDERAÇÕES FINAIS}

A dominação masculina é uma relação de poder exercida e naturalizada na sociedade. Esta relação de poder está enraizada na forma como a sociedade se organiza e é mantida através de micro práticas inseridas em todas os comportamentos e discursos, sendo estas denominadas micro machismos.

O presente trabalho tinha como objetivo principal analisar a presença destes micro machismos dentro do curso de Administração da UFPEL. Destrinchando este objetivo, pretendia também definir esta ideia de micro machismo e o que representa, definir algumas práticas que constituem os micro machismos, analisar como são ocorridas as práticas no ambiente do curso, e verificar a percepção dos alunos sobre o tema.

Através dos questionários aplicados em todos os alunos do curso, tanto homens quanto mulheres, e dos relatos voluntários prestados por quatro alunas de diferentes semestres, foi possível constatar que as quatro práticas de micro machismos investigadas ocorrem no curso. Há exemplos de promoção da "figura ideal feminina" nos exemplos dados em sala de aula, de constrangimentos sofridos pelas alunas quanto à forma de se portar e se vestir, no ambiente do curso e no mercado de trabalho, e de episódios em que as opiniões femininas foram desvalorizadas, por exemplo. Para uma melhor compreensão do fenômeno, é sugerido a realização de estudos futuros envolvendo a percepção das professoras e dos professores sobre o tema, e a pesquisa sobre outras práticas machistas que possam ocorrer. 


\section{REFERÊNCIAS}

ABRAMO, Laís. Custos do trabalho de homens e mulheres: mitos e realidade. Organização Internacional do Trabalho, 2014. Disponível em: $<$ http://www.ilo.org/wcmsp5/groups/public/---americas/---ro-lima/--ilobrasilia/documents/genericdocument/wcms_336484.pdf $>$. Acesso em: 28 mar. 2016

BEAUVOIR, Simone de. O Segundo Sexo. São Paulo: Nova Fronteira, 1980 BUTLER, Judith. Problemas de gênero: feminismo e subversão da identidade. Rio de Janeiro: Civilização Brasileira, 2003

CHIES, Paula Viviane. Identidade de gênero e identidade profissional no campo de trabalho. Revista de Estudos Feministas. Florianópolis, v. 18, n. 2, p. 352-360, mai./ago. 2010

FERREIRA, Aurélio Buarque de Holanda. Novo dicionário Aurélio da língua portuguesa. 3. ed. rev. e atual. Curitiba: Positivo, 2004

FONSECA, Rosa Maria Godoy Serpa da. Mulher e cidadania na nova ordem social. São Paulo: Núclero de Estudos da Mulher e Relações Sociais de Gênero (NEMGE/USP), 1996

FOUCAULT, Michel. Microfísica do Poder. Rio de Janeiro: Graal, 1979

INTERNATIONAL LABOUR ORGANIZATIOM. Women in business and management: gaining momentum. Geneva: ILO, 2015. Disponível em: < http://www.ilo.org/wcmsp5/groups/public/---dgreports/---dcomm/--

publ/documents/publication/wcms_334882.pdf>. Acesso em: 26 mar. 2016

LOURO, Guacira Lopes. Gênero, história e educação: construção e reconstrução. Educação e Realidade, Porto Alegre, v. 20, n. 2, p. 101-132, jul./dez. 1995

LOURO, Guacira Lopes. Gênero, sexualidade e educação: uma perspectiva pósestruturalista. Petrópolis: Vozes, 1999.

MACHADO, Roberto. Por uma genealogia do poder - Introdução. In: FOUCAULT, Michel. Microfísica do Poder. Rio de Janeiro: Graal, 1993.

NARVAZ, Martha Giudice; KOLLER, Sílvia Helena. Metodologias feministas e estudos de gênero: articulando pesquisa, clínica e política. Psicologia em Estudo, Maringá, v. 11, n. 3, p. 647-654, set./dez. 2006,

SCOTT, Joan. Gênero: uma categoria útil para análise histórica. Educação e Realidade, Porto Alegre, v. 20, n. 2, p. 71-99, jul./dez. 1995.

STEIL, Andrea Valéria. Organizações, gênero e posição hierárquica: compreendendo o fenômeno do teto de vidro. Revista de Administração da Universidade de São Paulo, v. 32, n. 3, p. 62-69, 1997. 